\title{
Influence of internal relative efficiency of steam turbine compartments on the performance of steam turbine cogeneration plant
}

\author{
Elena Stepanova* ${ }^{1}$, Alexey Maksimov ${ }^{1}$ \\ ${ }^{1}$ Melentiev Energy Systems Institute of Siberian Branch of the Russian Academy of Sciences, 130, Lermontov str., Irkutsk, 664033, \\ Russia
}

\begin{abstract}
The paper considers a steam turbine cogeneration plant that includes a back-pressure steam turbine and a natural gas-fired steam boiler that enables exhaust gas heat recovery, which is rather promising for the isolated heat and electricity consumers. A design and verification mathematical model of the steam turbine plant was developed. The focus is made on the optimization studies into the effect of the relative efficiency of turbine compartments on the performance indices of the steam turbine cogeneration plant with an installed electric capacity of $50 \mathrm{MW}$ that uses the heat of steam contained in the combustion products of the boiler for heating the feed-water of the heat network.
\end{abstract}

\section{Introduction}

The energy efficiency and cost-effectiveness of thermal power plants are largely determined by the performance of constituent heat and power units (HPU). Therefore, it is necessary to make balanced, optimal decisions both at the stage of their design, and at the stage of their operation. It is important to construct a proper flow diagram; choose basic and auxiliary equipment, its design characteristics; optimally distribute thermal and electrical loads of the main equipment, and use the technologies intended to enhance the HPU energy efficiency and cost-effectiveness. It is also necessary to take into account the influence of changes in the indices of critical technological processes, for example, the internal relative efficiency of turbine compartments (as one of the main values characterizing the level of turbine efficiency) [1], and constructional materials (metal strength characteristics of equipment operating at the highest temperatures, pressures, etc.) on the equipment characteristics. To accomplish the above tasks, we can use mathematical modeling and optimization. Melentiev Energy Systems Institute (MESI) SB RAS has developed the software package "Program building system" [2-4]. Extensive experience in mathematical modeling and optimization of various HPUs has been gained over a long period of the software operation. Moreover, the mathematical models of individual equipment components are used to describe in detail the processes taking place in them. These models rest on physical laws and existing methods intended for calculation of HPU components that are based on energy and material balances of energy carriers, processes of working medium expansion and contraction, as well as the normative method for thermal calculation of a boiler unit and others. This approach allows us to obtain detailed mathematical models of complex heat and power units; take into account various specific features of their operation; state and solve optimization problems.

\section{Problem statement}

Current reform of electricity and heating systems has an impact on the development of cogeneration related to the adoption of medium-capacity natural gas-fired cogeneration power plants, largely due to the introduction of greenhouse gas emissions control by countries. There are many off-grid electricity and heat consumers whose heat consumption considerably exceeds electricity consumption, and potential electricity production based on heat is much higher than the demand for electricity. In this situation, the combined cycle power plants and gas turbine plants using heat to generate a large amount of electrical energy that exceeds the needs may appear to be inefficient. Therefore, it can be more appropriate to use the plants for combined heat and power production with back-pressure steam turbines, which offer the possibility of heat recovery from exhaust gases of boilers. Such facilities increase possible volumes of heat and power cogeneration, enhance the fossil fuel efficiency, and reduce exhaust gas heat losses and nitrogen oxides emissions to the atmosphere, owing to their dissolution in condensed water vapor [5-9].

The authors of [10] propose a process flow diagram for a promising back-pressure steam turbine unit with a boiler equipped with a system for heat recovery of condensed water vapor of exhaust gases on the basis of absorption heat pumps that use bleed steam for industry

Corresponding author: step@isem.irk.ru 
as a heating medium. In [11], the authors present a flow diagram of a prospective steam turbine plant (Fig. 1). The main equipment of the plant is a back-pressure steam turbine and a natural gas-fired steam boiler, that provides exhaust gas heat recovery in the contact heat exchanger. The choice of the back-pressure turbine is justified by its simpler design and lower cost, compared to other types of steam turbines under the same value of the installed electric capacity, and also by the absence of condenser heat losses $[12,13]$. Due to the exhaust gas heat recovery, the steam turbine cogeneration plant will have lower exhaust gas heat losses, which will increase the boiler unit efficiency. The gas-fired steam turbine cogeneration plant has a number of advantages in comparison with the combined-cycle cogeneration plants and gas turbine units. These are: steam turbine is more reliable and has a longer service life than gas turbine; the materials used to manufacture steam boiler and steam turbine are less scarce than those of gas turbine.

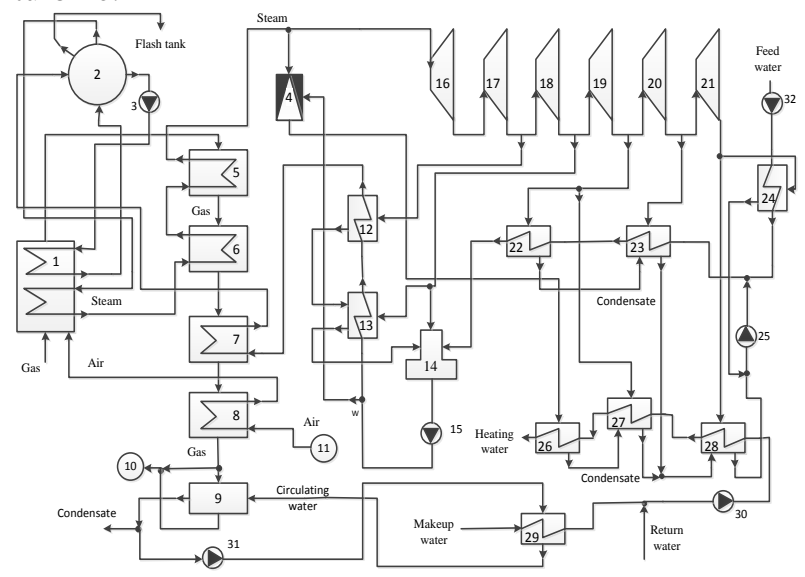

Fig. 1. A process flow diagram of the steam turbine cogeneration plant. 1 - furnace chamber; 2 - drum-separator; 4 - reduction-cooling unit; 5, 6 - superheater stages 1 and 2; 7 economizer; 8 - air heater; 9 - contact heat exchanger; 10 smoke exhauster; 11 - blowing fan; 12, 13 - high-pressure heaters; 14 - deaerator; 16-21 - steam turbine compartments; 22, 23 - low pressure heaters; 24 - primary cycle feed heater; 26-28 - network boilers 1,2, and 3, respectively; 29 - water-towater heater; $3,15,25,30,31,32$ - pumps.

This paper aims to investigate the effect of the internal relative efficiency of the steam turbine compartments on the indices of the steam turbine cogeneration plant proposed in [11]. This can prove worthwhile both to consider design options, and to operate the steam turbine cogeneration plant. The data obtained from analysis of the influence of the internal relative efficiency of the turbine compartments on the main performance characteristics of the plant make it possible to assess the level of reliability and efficiency in the stages of design and commissioning, and can also serve as a basis for planning and normalizing its future work. When operating the plant, it is necessary to identify the inefficient nodes and components, timely determine the measures to eliminate the flaws, and to evaluate the effectiveness of various measures undertaken to enhance the efficiency of the steam turbine plant.
A unified design and verification mathematical model of the cogeneration steam turbine has been developed. It contains a mathematical model for design calculation and four models for verification calculations. The design calculation was carried out under the maximum loads (nominal conditions), and determined design characteristics of the steam turbine equipment. The verification calculations were done for four characteristic conditions that have certain duration during the year, ambient air temperatures and heat loads. Different models of components were involved: for the design mathematical model, the models of all components are based on design calculations that determine geometric sizes of heat exchangers and nominal flow rates, inlet and outlet pressure of the steam turbine compartments. The verification mathematical model employs verification calculations that are performed for specified design characteristics and allow us to determine the parameters of working medium or heat carrier. The mathematical design and verification models of the steam turbine contain: models of compartments, regenerative high pressure and low pressure heaters, deaerator, and pumps. The mathematical design and verification models of the boiler unit include mathematical models of its components: water-cooled furnace, drum-separator, superheater, economizer, air heater, and pumps. The models of network boilers, a water-to-water heater of heat network feed water and a steam-to-water heater of feed water for the main cycle are also used. The peak heating of the network water is performed by steam from reduction-cooling unit (RCU). The RCU and peak heater are switched off when combined-cycle gas turbine plant operates under low network water temperatures. We have developed a model of contact heat exchanger for recovery of the exhaust gases heat of the boiler where flue gases and sprayed return water move in a vertical countercurrent. The return water (heated in the contact heat exchanger) is pumped in the water circuit and transfers heat to feed water in the water-to-water heat exchanger. The amount of return water increases due to the condensation of water steam from flue gases. The resulting excess of condensate can be fed into the condensate circuit after water treatment, or poured down the drain. Bypassing is provided to prevent condensate formation in the gas path and chimney, for the temperature of the gas mixture after the contact heat exchanger to be within $70-90{ }^{0} \mathrm{C}$ [9]. Bypassing is stopped in non-heating season, when there is no danger of condensation and icing in the gas path, because bypassing reduces the efficiency of the heat recovery process.

A flowchart of the devised design and verification mathematical model of the steam turbine cogeneration plant is shown in Fig. 2. We have also developed a block for calculation of annual technical-economic indices (fuel flow rate, heat and power production) and criteria of energy efficiency and cost-effectiveness (fuel heat utilization factor, extraction ratio, electrical efficiency, specific capital investment, etc.). 


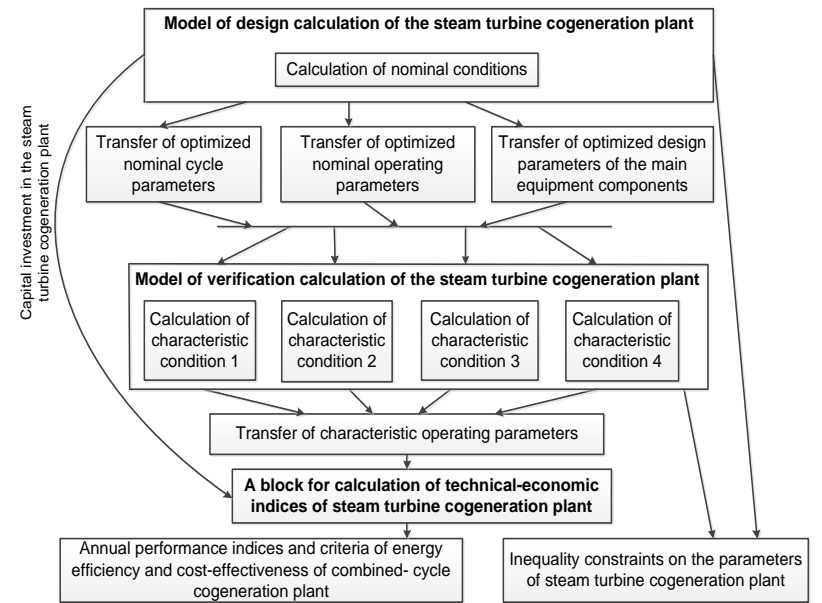

Fig. 2. A flowchart of the design and verification mathematical model of steam turbine cogeneration plant

In the optimization calculations using a single design and verification mathematical model, we assign the nominal cycle, design and operating parameters to be optimized. A change in the nominal cycle, design and operating parameters of the steam turbine plant affects the results of verification calculations of all characteristic conditions, while a change in the optimized operating parameters in one condition alters only the results of calculations of the specific characteristic condition to which they refer to $[2-4,14]$.

The electricity price was taken as an optimization criterion, at a given price of generated heat and the internal rate of return, which determines the level of economic viability of the investment project. A similar problem was solved in [14], where the price of generated heat was minimized at a given electricity price and an internal rate of return for combined-cycle plant. The differences between the studies described in this paper and the studies considered in [14] are as follows. In this paper, the optimization criterion is electricity price under a given heat price. This is due to a simpler heat price calculation based on an economic analysis of an alternative boiler plant. Since the operation of the studied steam turbine cogeneration plant depends on heat load, its electric power in the nominal and characteristic conditions depends on heat load, the required temperature of the network water, the distribution of the live steam between the reductioncooling unit and the turbine, and the consumption of natural gas burned in the boiler furnace. The heat price was determined as follows. The price of heat depends on the fuel component and semi-fixed costs. The fuel component is determined by the product of the specific fuel consumption per unit of generated heat and the fuel price. Semi-fixed costs depend on the specific investment in the plant. In the calculations, the specific fuel consumption and specific investment were assumed to be equal to these indices for the alternative gas-fired boiler with thermal output close to that of the considered plant. In the optimization calculations, we set a range of steam turbine electric power in the nominal conditions. The calculated heat load of the consumer is included in a set of the plant parameters to be optimized. This makes it possible to determine the optimal extraction ratio, i.e. the ratio of turbine heat output under the nominal conditions to the total heat output of the plant.

Mathematically, the optimization problem is written as follows.

$$
\min _{Q^{p}, x_{k}, B_{k}, x_{i}, B_{i}} C^{\text {elec }}
$$

subject to

$$
\begin{aligned}
& C^{\text {heat }}=f\left(C^{\text {fuel }}, R\right), \\
& S_{k}=f\left(x_{k}, B_{k}, \gamma_{k}, Q^{p}\right), \\
& G_{k}\left(x_{k}, B_{k}, \gamma_{k}, Q^{p}\right) \geq 0, \\
& x_{k}^{\min } \leq x_{k} \leq x_{k}^{\max }, \\
& N^{\min } \leq N_{k} \leq N^{\max } \\
& N_{k}=f\left(Q^{p}, B_{k}, x_{k}, \gamma_{k}\right), \\
& G_{i}\left(x_{i}, B_{i}, \gamma_{i}, S_{k}, Q_{i}\right) \geq 0, \\
& x_{i}^{\min } \leq x_{i} \leq x_{i}^{\max }, i=1, \ldots, n, \\
& K_{e q}=\theta\left(s_{k}, d_{s p}\right) \text {, } \\
& K_{\text {total }}=K_{e q}+K_{c} \\
& B_{\text {ann }}=\sum_{i=1}^{n} B_{i} T_{i}, \\
& Q_{i}=q_{i}\left(Q^{p}, \gamma_{i}\right) \text {, } \\
& N_{i}=f\left(Q_{i}, B_{i}, x_{k}, x_{i}, \gamma_{i}\right) \\
& Q_{\text {ann }}=\sum_{i=1}^{n} Q_{i} T_{i}, \\
& \ni_{\text {ann }}=\sum_{i=1}^{n}\left(N_{i}-N_{i}^{\text {aux }}\right) \cdot T_{i}, \\
& \operatorname{IRR}\left(B_{a n n}, Q_{a n n}, \ni_{\text {ann }}, C^{\text {heat }}, C^{\text {elec }}, K_{\text {total }},\right)=I R R_{Z}
\end{aligned}
$$

where $C^{\text {elec }}$ - electricity price, $x_{k}$ - vector of independent optimized parameters that determine design characteristics of the plant (cycle parameters, design parameters of components and nominal operating parameters); $x_{i}$ - vector of the optimized parameters in the $i$-th condition (index $i$ denotes the parameters that refer to the characteristic condition for which the verification calculations are performed); $B_{k}-$ hourly fuel flow rate by gas-fired boiler under nominal conditions; $B_{i}$ - fuel consumption by gas-fired boiler in the $i$-th condition; $C^{\text {heat }}$ - heat price; $C^{\text {fuel }}$ - fuel cost; $Q^{p}$ - calculated heat load; $R$ - constant component in 
the heat price; $S_{\kappa}$ - vector of design characteristics of the plant; $\gamma_{\kappa}$ - vector of initial data that determine the external conditions of the plant operation in the nominal conditions; $G_{k}-l_{k}$-dimensional vector function of inequality constraints in the nominal conditions; $N_{k}-$ total electric power in the nominal conditions; $N^{\mathrm{min}}$, $N^{\text {max }}$ - minimum and maximum value of electric power of the steam turbine cogeneration plant in the nominal conditions; $G_{i}-l_{p}$ - dimensional vector function of inequality constraints in the $i$-th condition; $\gamma_{i}$ - vector of initial data that determine external operating conditions in the $i$-th condition; $K_{e q}-$ capital investment in equipment; $d_{e q}$ - vector of specific cost of equipment components; $K_{\text {total }}-$ total capital investment; $K_{c}$ - capital investment considering unforeseen costs and construction costs; $B_{\text {ann }}-$ annual fuel consumption; $Q_{a n n}$ - annual heat output of the plant; $\ni_{a n n}-$ annual useful electricity output ; $T_{i}-$ duration of the $i$-th condition; $Q_{i}$ - heat output in the $i-$ th condition; $N_{i}-$ total electric power in the $i-$ th condition; $N_{i}^{\text {aux }}$ - auxiliary electricity consumption in the $i$-th condition; $I R R$ - internal rate of return; $I R R_{Z}$ - specified value of the internal rate of return; $\varphi-$ vector of parameters that determine the taxation and loan terms; $x_{k}^{\min }, x_{k}^{\max }, x_{i}^{\min }, x_{i}^{\max }-$ vectors of minimum and maximum values $x_{k}$ and $x_{i}$, respectively; $n$ - the number of conditions in which the verification calculations are carried out (the total number of characteristic conditions is $n+1$ ).

The list of design parameters to be optimized includes: the calculated heat load of the plant; fuel consumption of gas boiler; internal, external diameters and pitches of tubes of heating surfaces; height, width, depth of gas paths in superheaters and combustion chamber, steam and water mass velocities in them; outlet water and steam enthalpy of superheaters and economizer; inlet steam flow rate and pressure at the first network water heater, and extraction steam pressure.

The list of operating parameters to be optimized contains: fuel consumption of gas boiler; water flow rate in the drum-separator evaporative circuit; flow rate of heating water of the feed heater; inlet steam pressure of the first water heater; enthalpy and pressure of the steam going to the third network water heater after RCU. Constraints were imposed on the non-negativity of the temperature heads and flow rates of the plant working medium, and on the mechanical stress of the metal tubes of the heat exchangers. The total number of optimized parameters of the design and verification mathematical model of the steam turbine cogeneration plant is 72 , the number of inequality-constraints is 721 .

The initial information assumed in the calculation of capital investment [15] was as follows. Specific cost of: waterwall tubes of the boiler combustion chamber (steel
$12 \mathrm{X} 18 \mathrm{H} 12 \mathrm{~T})$ is 45 thousand $\mathrm{US} \$ / \mathrm{t}$; superheaters, economizer of the boiler (steel $15 \mathrm{X} 1 \mathrm{M} 1 \Phi$ ) - 30,6 thousand US\$/t, air heater of boiler, steam-to-water and water-to-water heat exchangers (steel 20) - 21 thousand US $\$ / t$. Specific cost of turbine generator and pumps is 60 US $\$ / \mathrm{kW}$, each; electrical equipment is 0,192 thousand US $\$ / \mathrm{kW}$, and systems that depend on fuel flow rate are US240 thousand $\$ / \mathrm{t} / \mathrm{h}$. Specific (per unit) capital investment in the fuel system is 14,4 thousand US $\$ / \mathrm{t} / \mathrm{h}$. Internal rate of return is 0.15 ; coefficient considering assembly costs is 1,6 ; coefficient that takes into account unforeseen costs is 1.03; coefficient that takes into account other costs is 1,3 ; coefficient of equipment price adjustment to current prices is 1.65 ; coefficient that takes into account the value of unconsidered equipment is 1,1 .

\section{Results of the optimization studies}

The optimization studies were carried out for the following climatic conditions: estimated ambient air temperature is $25{ }^{\circ} \mathrm{C}$, duration of the heating period is 4920 hours, non-heating period is 3840 hours.

Table 1. Optimal performance indices of steam turbine cogeneration plant for various values of internal relative efficiency of turbine compartments.

\begin{tabular}{|l|c|c|c|c|}
\hline \multicolumn{1}{|c|}{$\begin{array}{c}\text { Main performance } \\
\text { indices of steam turbine } \\
\text { plant }\end{array}$} & \multicolumn{3}{|c|}{$\begin{array}{c}\text { Internal relative efficiency of } \\
\text { turbine compartments }\end{array}$} \\
\cline { 2 - 5 } & $\mathbf{0 , 8 2}$ & $\mathbf{0 , 8 5}$ & $\mathbf{0 , 8 7}$ & $\mathbf{0 , 9 0}$ \\
\hline $\begin{array}{l}\text { Annual electricity } \\
\text { generation, thousand } \\
\text { MWh }\end{array}$ & 350,4 & 355,2 & 356,6 & 368,0 \\
\hline $\begin{array}{l}\text { Annual electricity output, } \\
\text { thousand MW h }\end{array}$ & 329,3 & 334,9 & 336,1 & 347,7 \\
\hline $\begin{array}{l}\text { Annual heat output, } \\
\text { thousand Gcal }\end{array}$ & 831,8 & 796,9 & 791,8 & 787,0 \\
\hline $\begin{array}{l}\text { Annual fuel consumption, } \\
\text { thousand tons of natural } \\
\text { gas equivalent (tnge) }\end{array}$ & 173,7 & 168,3 & 167,6 & 167,0 \\
\hline Extraction factor & 0,567 & 0,568 & 0,569 & 0,569 \\
\hline $\begin{array}{l}\text { Total investment, US\$ } \\
\text { mln }\end{array}$ & 34,58 & 34,38 & 34,37 & 34,37 \\
\hline $\begin{array}{l}\text { Specific capital } \\
\text { investment, US\$/kW }\end{array}$ & 689,0 & 687,4 & 687,2 & 684,5 \\
\hline $\begin{array}{l}\text { Fuel heat utilization } \\
\text { coefficient }\end{array}$ & 0,931 & 0,935 & 0,936 & 0,939 \\
\hline Electricity cost, cent / kW & 2,89 & 2,88 & 2,87 & 2,86 \\
\hline $\begin{array}{l}\text { Live steam flow rate for } \\
\text { the turbine in nominal } \\
\text { conditions, kg/s }\end{array}$ & 71,3 & 68,1 & 67,6 & 67,3 \\
\hline $\begin{array}{l}\text { Live steam pressure in } \\
\text { nominal conditions, } \\
\text { kg/cm2 }\end{array}$ & 88,7 & 88,6 & 88,5 & 88,5 \\
\hline $\begin{array}{l}\text { Live steam temperature in } \\
\text { nominal conditions, }{ }^{0} \mathrm{C}\end{array}$ & 525 & 525 & 525 & 525 \\
\hline $\begin{array}{l}\text { Steam flow rate after the } \\
\text { last turbine stage in } \\
\text { nominal conditions, kg/s }\end{array}$ & 46,4 & 44,7 & 42,1 & 42,0 \\
\hline $\begin{array}{l}\text { Steam pressure after the } \\
\text { last turbine stage in } \\
\text { nominal conditions, } \\
\text { kg/cm2 }\end{array}$ & 1,53 & 1,50 & 1,48 & 1,46 \\
\hline $\begin{array}{l}\text { Fuel flow rate in nominal } \\
\text { conditions, tnge/h }\end{array}$ & 37,5 & 36,9 & 36,7 & 36,5 \\
\hline
\end{tabular}


The year is divided into a heating period with three time intervals with ambient temperatures equal to $-20^{\circ} \mathrm{C}$, $-10^{\circ} \mathrm{C},+1.5^{\circ} \mathrm{C}$, and a non-heating period with a temperature of $+18^{\circ} \mathrm{C}$. The range of variation in the steam turbine electric power was 50-60 MW. The temperature chart of the heat network was assumed equal to $150 / 70^{\circ} \mathrm{C}$. The fuel price is $\$ 100$ per tce. The heat cost is $20 \$ / G c a l$. Based on the methodological approach described above, we studied the impact of the internal relative efficiency of turbine compartments on the main performance indices of the plant, the integral indices of the plant, namely, the fuel heat utilization coefficient (FHUC) and the electricity cost for the considered steam turbine cogeneration plant. A series of optimization calculations were performed in which the internal relative efficiency of the turbine compartments varied in the range from 0,82 to 0,9 . Table 1 shows the main performance indices of the steam turbine plant that were obtained from the optimization calculations for different values of the internal relative efficiency of the turbine compartments. Table 2 demonstrates some of the basic design characteristics of the plant equipment that were calculated with an internal relative efficiency of the turbine compartments equal to 0,87 .

Table 2. Main design characteristics of steam turbine cogeneration plant equipment, obtained for the internal relative efficiency of turbine compartments equal to 0,87 .

\begin{tabular}{|c|c|}
\hline Design characteristics & Values \\
\hline $\begin{array}{l}\text { Boiler furnace: } \\
\text { - height, m } \\
\text { - width, } m \\
\text { - depth, m } \\
\text { - outer/inner diameter/pitch of evaporating } \\
\text { surface tubes, mm } \\
\text { - outer/inner diameter /pitch of superheating } \\
\text { surface tubes, mm }\end{array}$ & $\begin{array}{c}22,0 \\
9,0 \\
9,0 \\
60 / 50 / 80 \\
60 / 50 / 64\end{array}$ \\
\hline $\begin{array}{l}\text { Superheater of the 1st stage of the boiler: } \\
\text { - an outer/inner diameter of tubes, mm } \\
\text { - a transverse/longitudinal pitch of tubes, mm } \\
\text { - area of heat transfer surface, } \mathrm{m}^{2}\end{array}$ & $\begin{array}{l}32 / 20 \\
80 / 60 \\
200,0\end{array}$ \\
\hline $\begin{array}{l}\text { Superheater of the } 2 \text { nd stage of the boiler: } \\
\text { - an outer/inner diameter of tubes, mm } \\
\text { - a transverse/longitudinal pitch of tubes, mm } \\
\text { - area of heat transfer surface, } \mathrm{m}^{2}\end{array}$ & $\begin{array}{l}32 / 20 \\
80 / 60 \\
660,0\end{array}$ \\
\hline $\begin{array}{l}\text { Boiler economizer: } \\
\text { - an outer/inner diameter of tubes, } \mathrm{mm} \\
\text { - a transverse/longitudinal pitch of tubes, } \mathrm{mm} \\
\text { - area of heat transfer surface, } \mathrm{m}^{2}\end{array}$ & $\begin{array}{r}32 / 28 \\
60 / 45 \\
2959,0 \\
\end{array}$ \\
\hline $\begin{array}{l}\text { Boiler air heater: } \\
\text { - an outer/inner diameter of tubes, mm } \\
\text { - a transverse/longitudinal pitch of tubes, mm } \\
\text { - area of heat transfer surface, } \mathrm{m}^{2}\end{array}$ & $\begin{array}{c}40 / 35 \\
60 / 45 \\
3990,0 \\
\end{array}$ \\
\hline $\begin{array}{l}\text { Area of heat transfer surface of high-pressure } \\
\text { heaters of turbine unit, } \mathrm{m}^{2} \text { : } \\
\text { - heater } 1 \\
\text { - heater } 2\end{array}$ & $\begin{array}{l}300,0 \\
150,0\end{array}$ \\
\hline $\begin{array}{l}\text { Area of heat transfer surface, } \mathrm{m}^{2}: \\
\text { - network heater } 1 \\
\text { - network heater } 2 \\
\text { - network heater } 3 \\
\text { - a water-to-water heater of network water }\end{array}$ & $\begin{array}{c}1102,0 \\
628,0 \\
1150,0 \\
5912,0\end{array}$ \\
\hline
\end{tabular}

Figure 3 presents the fuel heat utilization coefficient versus the change in the internal relative efficiency of turbine compartments. Figure 4 shows the relationship between the cost of electric energy and a change in the internal relative efficiency of turbine compartments.

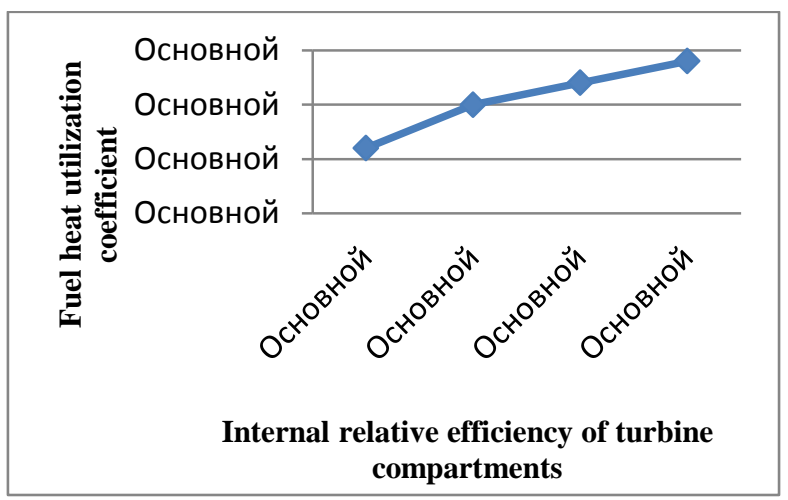

Fig. 3. Fuel heat utilization coefficient depending on the internal relative efficiency of turbine compartments.

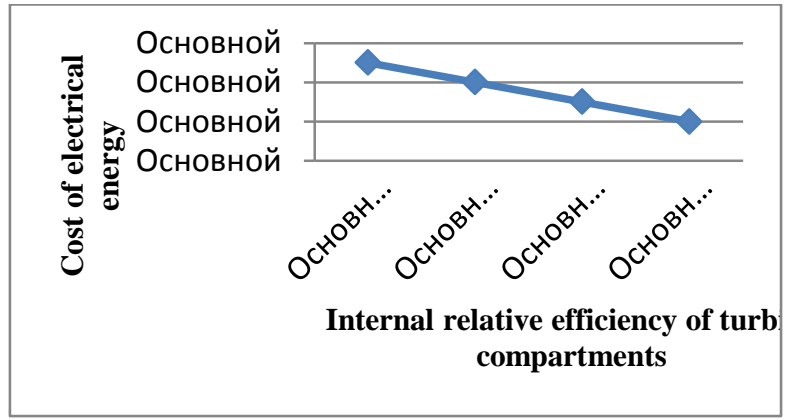

Fig. 4. Cost of electrical energy generated by the steam turbine cogeneration plant depending on the internal relative efficiency of turbine compartments.

\section{Conclusions}

An analysis of the results of optimization studies indicates the following.

- As seen in Figure 3, an increase in the internal relative efficiency of the turbine compartments from 0,82 to 0,9 leads to a rise in the fuel heat utilization coefficient from 0,931 to 0,939 . These values show the effective fuel heat consumption and are conditioned by the choice of a back-pressure steam turbine and steam boiler as constituents of the steam turbine plant flow diagram. The back-pressure turbine has no heat loss in the cooling water condenser and the natural gas-fired steam boiler makes it possible to recover the exhaust gas heat. The coefficient of fuel heat utilization for a cogeneration plant of the same capacity but with a turbine that has a condenser but no recovery of exhaust gas heat is not higher than 0,8 .

- The results of the optimization calculations presented in Fig. 4 indicate that the cost of electricity generated by the steam turbine cogeneration plant virtually linearly depends on the internal relative efficiency of the turbine compartments, and when the internal relative efficiency of the turbine compartments changes from 0,82 to 0,9 , the cost of electric energy decreases by 0,03 cents $/ \mathrm{kW}$. Given the electrical energy output, the economic effect 
of the efficiency increase from 0,82 to 0,9 will be 98,79 thousand US\$/year. This allows us to estimate the rational costs of enhancing the internal relative efficiency of steam turbine compartments.

- The additional amount of heat obtained by recovery of the exhaust gas heat when the feed water of the network water is heated lies in the range from $38,4 \mathrm{Gcal} / \mathrm{h}$ to 39,3 $\mathrm{Gcal} / \mathrm{h}$, which is approximately $22 \%$ of the calculated heat load.

- The temperature of the exhaust gases after the contact heat exchanger when the steam turbine plant is operating during the heating period is in the range from $84{ }^{\circ} \mathrm{C}$ to 87 ${ }^{0} \mathrm{C}$. This excludes the possibility of condensate formation in the gas path and chimney and reduces thermal emissions from the plant.

- The extraction factor of the steam turbine plant is equal to a ratio of the heat obtained from the turbine steam to the total heat output and lies in the range from 0,567 to 0,569 . This means that in the nominal conditions, the heat of extracted steam covers a large proportion of the heat load.

\section{Acknowledgments}

This work was carried out at Melentiev Energy Systems Institute of Siberian Branch of the Russian Academy of Sciences and the framework of the scientific project III.17.1.1. program of fundamental research of the SB RAS, reg. No. AAAA-A17-117030310433-6

\section{References}

1. Filipov G.A., Gribin V.G., Avetisyan A.R., Lisyansky A.S. Analysis of the influence of individual components of losses due to humidity on the economics of steam turbine stage and compartments// Thermal Engineering, 2015, No. 1, p. 22-28.

2. Kler A.M. Dekanova N.P., Shchegoleva T.P. Methods for optimization of complex energy plants. - Novosibirsk: "Nauka". Sib. Ed. Firm, 1993. - 116 p.

3. Kler A.M., Dekanova N.P., Skripkin S.K. and others. Mathematical modeling and optimization in the tasks of operational control of thermal power plants. - Novosibirsk: Nauka. Sib. Enterprise of the Russian Academy of Sciences, 1997. - 120 p.

4. Kler A.M., Tyurina E.A. Optimization studies of power plants and complexes. - Novosibirsk: Academic Publishing House "Geo", 2016. - 298 p.

5. Hazell D. Modeling and Optimization of Condensing Heat Exchangers for Cooling Boiler Flue Gas, 2011, 108 pages.

6. Terhan M, Comakli K. Design and economic analysis of a flue gas condenser to recover latent heat from exhaust flue gas. Appl. Therm. Eng. 2016;100(3):1007-1015.

7. Sheng Shang, Xianting Li,Wei Chen, Baolong Wang, Wenxing Shi. A total heat recovery system between the flue gas and oxidizing air of a gas-fired boiler using a noncontact total heat exchanger. Applied Energy. Volume 207, 1 December 2017, Pages 613-623.

8. Aronov I.Z., Presich G.A. Experience in operating contact economizers at Pervouralskaya CHPP. - Industrial Power Engineering, 1991, No. 8.

9. Shadek E., Marshak B., Anokhin A., Gorshkov V. Advanced recovery of heat from heat generator flue gases.
- Industrial and heating boiler plants and mini-CHPPs, 2014, No. 2.

10. Stennikov V.A., Zharkov S.V. Effective Directions of Technical Policy in Energy Supply // Izvestiya RAN. Power Engineering. №5. 2017. P.19-31.

11. Stepanova E.L., Zharkov S.V. Mathematical model of CHPP given the recovery of combustion products heat. Collected papers: The efficiency enhancement of energy generation and use in Siberia. Materials of the All-Russian Scientific and Practical Conference with international participation in 2 volumes. Irkutsk National Research Technical University; 2017. P. 271-274.

12. Chistovich S.A. About application of combined cycle plants with back-pressure turbines in the city building areas. - Heat supply news, 2011, № 1.

13. Bozhko V.V., Shargorodsky V.S., Rozenberg S.Sh., Leonova I.S., Khomenok LA, Makarov A.N., Krotov K.V. Modernization of turbines of type "R" with the purpose of their transfer from back pressure to extraction operation. Experience in the operation of modernized turbines. - Heat supply news, 2006, № 2.

14. Kler A.M., Potanin Yu.M., Maksimov A.S. Consideration of the variable nature of thermal loads in the optimization of thermal power plants / / Thermal Power Engineering, 2012, N7, p.63-69.

15. Kler A.M., Potanina Yu.M., Epishkin N.O. Influence of boiler steels on the parameters of a coal-fired power unit // Proceedings of the Russian Academy of Sciences. Power Engineering.-2015.-No.5-P.106-111. 